\title{
Uma leitura sobre a produção de conhecimentos matemáticos e financeiros por alunos do Ensino Médio no processo de tomada de decisão entre comprar ou alugar um imóvel
}

\author{
Ivail Muniz Junior \\ Colégio Pedro II/FAETEC, PEP da COPPE-UFRJ \\ ivailmuniz@gmail.com
}

\section{Samuel Jurkiewicz}

Universidade Federal do Rio de Janeiro / PEP da COPPE-UFRJ

jurki@pep.ufrj.br

\begin{abstract}
Resumo
Esse artigo apresenta uma análise da produção e articulação de conhecimentos matemáticos e financeiros por estudantes de Ensino Médio em uma atividade envolvendo a decisão entre comprar ou alugar um imóvel. Utiliza-se o Modelo dos Campos Semânticos (LINS,1999) como base teórico-metodológica e como instrumento de leitura das produções de significados e conhecimentos dos sujeitos investigados, realizada a partir da produção de dados capturados por vídeos, adaptada da proposta de Powell (2004). Os resultados iniciais, obtidos a partir da análise das estratégias e discursos apresentados, mostraram uma dinâmica envolvendo uma rede de conhecimentos matemáticos articulados a aspectos financeiros, culturais e comportamentais.
\end{abstract}

Palavras-chave: Abordagem de situações financeiras. Matemática Financeira. Produção de conhecimentos e significados. Campos Semânticos.

\section{A reading on the production of mathematical and financial knowledge for high school students in the decision-making process between buying or renting a property}

\begin{abstract}
This paper presents an analysis of the production and articulation of mathematical and financial knowledge by students of high school in an activity involving the decision between buying or renting a property. We use the model of Semantic Fields (LINS,1999) as a theoreticalmethodological basis and as a reading tool for productions of meaning and knowledge of the subjects, made from the production data captured by video, adapted the proposed Powell (2004). The initial results obtained from the analysis of the presented strategies and speeches showed a dynamic involving a network of articulated mathematical knowledge the financial, cultural and behavioral.
\end{abstract}

Keywords:Approach to financial situations. Financial Math. Production of knowledge and meanings. Model of Semantic Fields. 


\section{Introdução}

As transformações econômicas ocorridas nas últimas duas décadas, tais como a estabilidade da moeda, o aumento da renda, o crescimento da classe média brasileira, o aumento da oferta de crédito para bens (móveis ou imóveis) e serviços, a ampliação do prazo dos financiamentos imobiliários, a velocidade da geração e do consumo de bens e serviços, além do aumento da expectativa de vida da população, juntamente com a crise internacional de 2008 e seus desdobramentos globais sentidos até hoje, têm impactado fortemente a vida do brasileiro. Tais transformações também têm contribuído para ampliar o debate sobre questões econômicas e financeiras em diversos setores da sociedade.

É nesse contexto dinâmico e repleto de desafios, informações e tomada de decisões que a abordagem de situações econômico-financeiras na Educação Básica se insere e sofre influência, em especial no Ensino Médio, conforme aponta Muniz (2010).

Temos defendido que a escola pode ser um espaço privilegiado de produção de conhecimento que contribua, de forma compartilhada com a família, para a reflexão e ação em tais situações.

A abordagem de situações econômico-financeiras (SEF) no Ensino Médio brasileiro geralmente está associada a alguns (poucos) conceitos de matemática financeira, os quais estão presentes em praticamente todos os livros didáticos de matemática recém publicados para o Ensino Médio ${ }^{1}$. Além da matemática financeira, temas relacionados ao planejamento financeiro, consumo, renda e poupança têm começado a fazer parte do projeto político pedagógico de algumas escolas, muitas vezes com o nome de Educação Financeira ou Educação para o consumo².

Em outros casos, variados tipos de Educação Financeira aterrissam nas escolas por meio de iniciativas do Governo Federal ${ }^{3}$, Bancos, Instituições Financeiras, Seguradoras, ONGs, dentre outras. As intenções são extremamente variadas e geralmente associadas aos interesses dos agentes que financiam e promovem tal educação financeira, conforme podemos ver em trabalhos recentes de Saito (2008), Brito (2012) e Muniz (2013).

Esse cenário econômico, juntamente com o aumento dessas iniciativas, pode ter influenciado no aumento do número de pesquisas em Educação Matemática que tem como alvo a abordagem de Situações Econômico-Financeiras (SEF), conforme apontado por Rolim e Mota (2014).

\footnotetext{
${ }^{1}$ Baseado no Programa Nacional do Livro Didático - PNLD de 2015.

${ }^{2}$ Um mapeamento está disponível em http://www.vidaedinheiro.gov.br/docs/RelatorioEstatisticoENEF.pdf

${ }^{3}$ Os portais digitais http://www.edufinanceiranaescola.gov.brhttp://www.aefbrasil.org.br/index.php/programas-e-projetos/educacaofinanceira-nas-escolas/,são apenas alguns exemplos dessas iniciativas.
} 
Algumas das pesquisas mais recentes têm investigado a construção e articulação de conhecimentos matemáticos e não matemáticos por alunos do Ensino Médio na análise de situações financeiras, dentre elas Novaes (2009) e Muniz (2014). Por outro lado, outras pesquisas têm utilizado uma perspectiva mais humanista, ou seja, têm dado foco a questões comportamentais, éticas e de sustentabilidade envolvendo as situações econômico-financeiras, tais como as realizadas por integrantes do NIDEEM/GRIFE do Departamento de Educação Matemática da UFJF, tais como Kistemann (2011), Brito (2012), Campos (2013), Barroso (2013), dentre outros.

O caminho de pesquisa que temos construído é inspirado e motivado pela experiência em sala de aula com a abordagem dessa temática nas aulas de Matemática no Ensino Médio e Técnico, desde 2001; pela experiência com as disciplinas da área de Pesquisa Operacional na construção e utilização de modelos matemáticos na resolução de problemas, muitas vezes interdisciplinares, envolvendo tomada de decisão; pela Educação Matemática Crítica (SKOVSMOSE, 2001); pela Psicologia Cognitiva e pelos estudos sobre Modelagem Matemática na Educação Matemática.

Nesse caminho está este artigo que tem como objetivo apresentar duas análises sobre a produção de conhecimentos e significados por um grupo de alunos do Ensino Médio de uma Escola Estadual no Rio de Janeiro, quando investigaram uma situação-problema envolvendo o processo de tomada de decisão entre comprar ou alugar um imóvel.

A primeira análise é sobre a construção e articulação de ideias e modelos matemáticos e financeiros pelos estudantes e a influência destes em suas decisões finais. A segunda análise recai sobre outros aspectos que emergiram dos discursos dos estudantes quando analisavam a situação proposta, que articulados com os resultados produzidos pelos modelos construídos e utilizados por eles, poderiam interferir em seus processos de tomada de decisão.

Adotamos o Modelo dos Campos Semânticos (LINS, 1999) (MCS) como base teóricometodológica e como instrumento de leitura das produções de significados e e conhecimentos dos sujeitos da pesquisa. Tal leitura foi feita a partir de dados produzidos ${ }^{4}$ e capturados em vídeo, que foram organizados e analisados com aporte na metodologia apresentada em Powell et al (2004) e Powell \& Quintaneiro (2015).

\section{Concepções e referenciais teóricos}

Começo focando em nossas concepções sobre a abordagem de SEF na escola, aqui em especial no Ensino Médio, compreendendo que esta deve ser um convite à reflexão, ou seja, deve oferecer oportunidades de investigação de situações financeiras, relacionadas ao modo de pensar e agir dos

\footnotetext{
${ }^{4}$ Usamos o termo produção de dados, conforme Powell (2004), em lugar coleta de dados, com o sentido de reconhecer que o pesquisador intervém na realidade e seleciona um recorte dela.
} 
indivíduos dentro da sociedade, através da articulação da matemática escolar com outros saberes de forma crítica, reflexiva e colaborativa. Tal abordagem não pode ignorar que as situações financeiras a serem analisadas estão envolvidas com questões econômicas, sociais, comportamentais, antropológicas, ambientais, em que o pensar e agir financeiramente interfere na vida do indivíduo e impacta na vida em sociedade.

A partir desse cenário multidisciplinar, montamos uma estrutura que sintetiza os aspectos levados em consideração em nossa abordagem, composta de quatros aspectos: conceituais, contextuais, didáticos e comportamentais. Essa estrutura pode representada através do esquema a seguir.

Figura 1 - Os quatro aspectos presentes na abordagem de SEF na Escola utilizada na pesquisa.

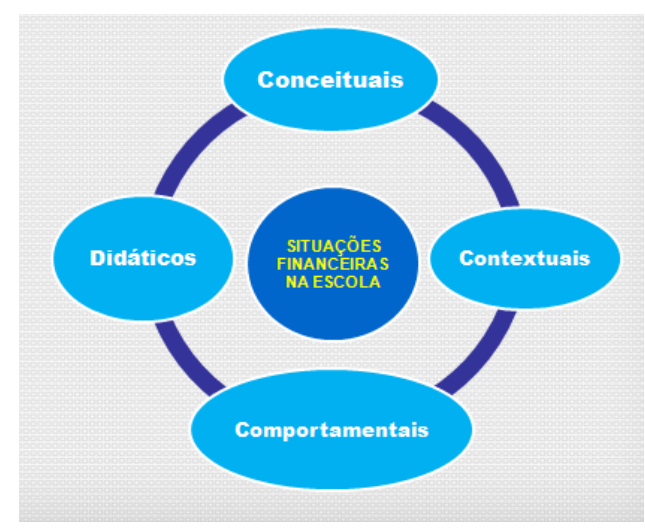

Fonte: MUNIZ, 2014

Os aspectos conceituais se referem às noções de porcentagem, crescimentos exponenciais, progressões geométricas, gráficos de funções; às noções econômicas, tais como renda, demanda, oferta, taxas de juros, inflação, etc; e às noções financeiras como cartão de crédito, cheque especial, aluguel, prestação, financiamento, etc.

Os aspectos contextuais se referem ao ambiente em que acontecem as situações, e suas transformações, tais como as condições econômicas de uma região em um dado momento, ou de um indivíduo e/ou sua família, as situações contingenciais, as fases da vida, os hábitos de algum grupo ao qual pertence, dentre outros.

Os aspectos comportamentais, muito estudados pela Psicologia Cognitiva, estão presentes nessa abordagem na medida em que as pessoas levam em consideração seus desejos, o status, o poder, impulsos, reconhecimento no grupo, estado emocional, humor, dentre outros aspectos, quando fazem escolhas diante de situações financeiras.

Os aspectos didáticos se referem a como abordar tais situações a partir das disciplinas escolares, em especial a matemática. Como a matemática pode ajudar a compreender situações financeiras? Como abordar determinadas noções financeiras na aula de matemática? Como usar tecnologia para isso? Essas são apenas algumas perguntas associadas a esses aspectos. 
Essa abordagem, portanto, se diferencia da Educação Financeira de bancos e algumas outras instituições financeiras, na medida em que se volta para as questões de ensino e aprendizagem de matemática sem desconsiderar os diversos contextos e comportamentos presentes na sociedade. A educação Financeira dos bancos ou da Organização para Cooperação do Desenvolvimento Econômico (OCDE) não parece estar preocupada com tais questões didáticas e dá pouca ou nenhuma atenção para a articulação entre conhecimentos construídos pelas crianças e jovens na escola para além da compreensão de produtos financeiros.

Buscamos, com essa abordagem, que os alunos se beneficiem da matemática para analisar situações financeiras e tomar decisões, bem como investiguem tais situações para aprender matemática. A abordagem de SEF na Escola que propomos é uma via de mão dupla, em que a relação entre ensino de matemática e a abordagem de situações financeiras sejam dois lados de uma mesma moeda.

Nessa visão, não dizemos o que os estudantes devem fazer, nem definimos a melhor decisão a ser tomada, considerando apenas um único ponto de vista (o financeiro, por exemplo), ou ainda qual o aspecto deve ser predominante em suas escolhas. Optamos por outra direção, na qual buscamos oferecer oportunidades de reflexão aos estudantes através da leitura de situações financeiras que contemple ideias matemáticas e não-matemáticas, para que eles avaliem e tomem suas próprias decisões.

A abordagem que apresentamos e todos os seus pressupostos têm forte ligação com a Educação Matemática Crítica de Ole Skovsmose (2001), na medida em que os alunos se envolvem com toda a construção do conhecimento e com o processo de ensino-aprendizagem, além de se referirem a problemas sociais objetivamente existentes.

Em nossa pesquisa, adotamos o Modelo dos Campos Semânticos (MCS) proposto por Lins (1999) como base teórico-metodológica e como instrumento de leitura das produções de significados e construção de conhecimento dos sujeitos da pesquisa. Nossa concepção de conhecimento vem desse modelo, em que o conhecimento não pode ser transmitido, mas sim produzido pelo sujeito a partir da produção de significados. Deste modo, conhecimento está diretamente ligado às concepções dos sujeitos que o produzem.

Segundo Lins (1999), “conhecimento é uma crença-afirmação junto com uma justificação que autoriza a produzir aquela enunciação”. Além disso, conhecimento é algo do domínio da enunciação, e sempre há um sujeito do conhecimento. Assim, nessa perspectiva, não há conhecimento em livros, pois ali há apenas enunciados. É preciso a enunciação efetiva daqueles enunciados para que eles tomem parte na produção de conhecimentos (LINS, 1999, pp. 88 e 89 ). 
No que diz respeito ao que é significado de um objeto, usamos a noção de que é aquilo que efetivamente se diz a respeito desse objeto no interior de uma atividade, e objeto é aquilo para o que se produz significado (LINS, 1993, p.86).

Em nossa análise, consideramos também que conhecimento é algo individual - aquilo que o sujeito efetivamente produz a partir de suas ações enunciativas ${ }^{5}$ em relação a objetos, no interior de uma atividade - mas fortemente ligado ao coletivo, ao meio, à atividade. Com isso queremos ler o outro, e para isso queremos entender (i) quais objetos ele constituiu; (ii) quais foram suas estipulações locais, as operações utilizadas e sua lógica; (iii) que conhecimento produziu e (iv) na direção de quais interlocutores o fez, e em que (ou quem) se justifica para dizer o que disse, conforme proposto por Silva (2003, p.66). Esse processo nos ajudou a mapear as estratégias usadas pelos alunos em suas investigações para a situação-problema apresentada.

A concepção de atividade aqui é composta do ambiente da sala de aula, dos estudantes investigados, do pesquisador, das interações entre eles e da tarefa apresentada na forma de uma situação-problema.

\section{Metodologia da Pesquisa}

A atividade que será analisada nesse artigo, focará nos discursos produzidos pelos alunos, nos quais identificamos ideias, estratégias e, de uma forma geral, o pensamento matemático dos alunos e sua articulação com outros aspectos, em atividades envolvendo a tomada de decisão na situação apresentada na tarefa.

O grupo investigado contou com a participação voluntária de oito alunos da segunda série do Ensino Médio de uma Escola Técnica Estadual no Rio de Janeiro, em Nova Iguaçu. Eles se dividiram em dois grupos, sendo o Grupo 1 (G1) formado por Lucas, Roger, João e José; e o Grupo 2 (G2) formado por Evelin, Bruna, Preta e Clara.

O encontro, realizado em 2014, se dividiu em duas partes. Na primeira, com duração de 60min, uma situação-problema foi apresentada aos alunos envolvendo um dilema vivido por um casal que precisava decidir entre comprar ou alugar um imóvel, e os alunos trabalharam em grupos durante aproximadamente 1 hora. Na segunda, com duração de 90min, os integrantes dos grupos apresentaram oralmente suas ideias e estratégias para justificar suas tomadas de decisão, interagindo entre si nos acordos e nas controvérsias, usando um quadro branco para auxiliar em suas exposições. As discussões foram mediadas pelo pesquisador. Analisaremos apenas alguns eventos ocorridos na segunda parte do encontro.

\footnotetext{
${ }^{5}$ Entendemos por ações enunciativas com sendo formas de expressar o que se diz, tais como falas, escritas, gestos, desenhos, gráficos, e até mesmo, em alguns casos, o silêncio.
} 
Os alunos já haviam estudado porcentagens, taxas de crescimento, fatores de atualização, equivalência de capitais e séries uniformes. Ou seja, sabiam a forma mais usual de transformação do dinheiro no tempo, em que a taxa incide sobre o saldo acumulado do período anterior.

Para a produção de dados, optamos pelas tecnologias de vídeo, pois fornecem maneiras de recolher, compartilhar, estudar, apresentar, e arquivar casos detalhados de prática para apoiar o ensino, o aprendizado e o estudo intensivo e prolongado dessas práticas (POWELL \& QUINTANEIRO, 2015, p.4).

Dado o nosso olhar para os processos dos alunos, e não simplesmente para suas respostas ou decisões finais, a escolha por registros em vídeo também nos permitiu esclarecer dúvidas, acessar detalhese reexaminar processos vivenciados pelos alunos, incluindo os pontos divergentes e contraditórios. Esse tipo registro, através de múltiplas imagens, nos permitiu, por exemplo, compreender melhor o caminho que eles trilharam para chegar às soluções e decisões finais, conforme veremos mais adiante.

\section{Análise dos Resultados}

A tarefa apresentada aos alunos consistia de uma situação problema em que um casal hipotético construiu duas estratégias, sendo a primeira comprar um apartamento, através de uma entrada, usando uma economia do casal destinada a esse fim, e de um financiamento. A segunda seria alugar o apartamento em vez de comprá-lo, conforme mostra a Figura 2.

Figura 2 - Tarefa apresentada aos alunos

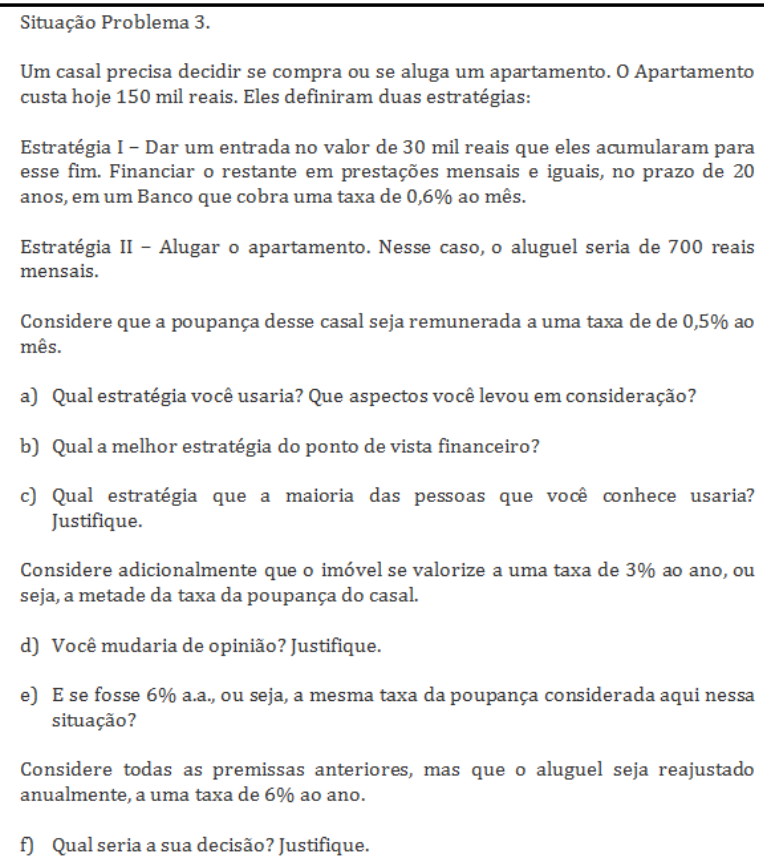

Fonte: Elaborada pelos autores. 


\section{Análise das estratégias apresentadas pelo Grupo 1}

O grupo começou reunindo os dados no quadro e partiu do valor a ser financiado em 120 mil reais, devido à entrada de 30 mil, para em seguida calcular o valor das prestações do financiamento, a partir da equação que relacionava o valor da prestação (P) com o valor a ser financiado (VP), a taxa de juros mensais (i) e o prazo do financiamento (n), encontrando 944,82, conforme ilustra a figura abaixo.

Figura 3 - Estratégia inicial do Grupo 1 - encontrar o valor da prestação do financiamento

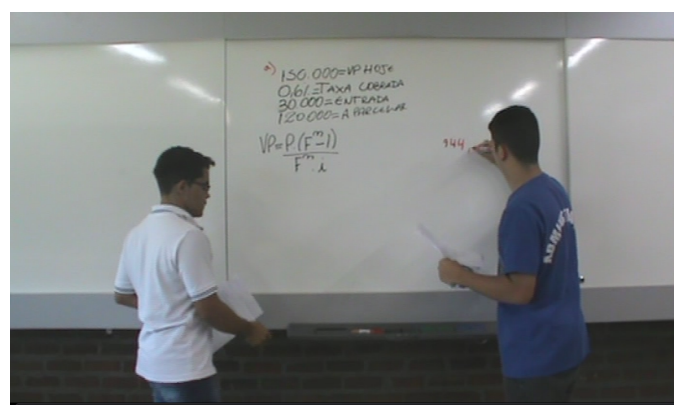

$$
120.000=P \frac{\left(1,006^{240}-1\right)}{1,006^{240} \cdot 0,006}
$$

Fonte: Elaborada pelos autores.

O pesquisador fez uma sondagem inicial, após os alunos apresentarem o valor da prestação, para identificar os primeiros significados produzidos por eles em relação à tomada de decisão. A transcrição a seguir apresenta os discursos nesse primeiro momento.

Figura 4 - Impressões iniciais dos grupos sobre a decisão

\begin{tabular}{|c|c|c|}
\hline $06: 03$ & Lucas & $\begin{array}{l}\text { Nós pensamos o seguinte. Que a prestação seria o valor maior, isso no } \\
\text { início! Só olhando, só com essa conta. Agente pensou que a prestação } \\
\text { seria maior, porém ao final, o cara teria a casa. Isso a gente pensou de } \\
\text { início. }\end{array}$ \\
\hline 07:04 & Pesq & $\begin{array}{l}\text { O que o outro grupo achou inicialmente quando vocês encontraram essa } \\
\text { prestação maior que o aluguel? }\end{array}$ \\
\hline 07:18 & Evelin & $\begin{array}{l}\text { A mesma coisa. Por mais que a prestação fosse mais cara, no final das } \\
\text { contas teríamos um bem, no caso a casa. }\end{array}$ \\
\hline $07: 34$ & Pesq & $\begin{array}{l}\text { Ah! [..] Esse valor colocou vocês em que direção inicial: em comprar ou } \\
\text { em alugar? }\end{array}$ \\
\hline 07:52 & Lucas & Logo que olhou a gente pensou em comprar. \\
\hline 08:05 & Evelin & $\begin{array}{l}\text { A gente pensou em fazer conta. Não vamos tomar nenhuma decisão } \\
\text { agora. Melhorfazer as contas pra ver qual a melhor decisão. }\end{array}$ \\
\hline 08:17 & Preta & $\begin{array}{l}\text { Mas a gente achou a mesma coisa [se referindo ao dito pelo outro grupo] } \\
\text { que seria melhor comprar, porque mesmo sendo maior o valor não é tão } \\
\text { grande, e gente pensou no bem. }\end{array}$ \\
\hline
\end{tabular}

Fonte: Elaborada pelos autores.

Apesar do valor da prestação ser maior que o do aluguel, os dois grupos ficaram inclinados inicialmente a comprar o apartamento, pois segundo os dois grupos, ao final o casal teria um bem. Os valores da prestação e do aluguel foram objetos constituídos pelos alunos a partir dos quais realizaram operações, usando a lógica da transformação do dinheiro no tempo. A comparação inicial entre o maior e o menor não levou a uma opção pelo menor, pois ao final se teria um bem, 
conforme registrado na transcrição anterior. Mas não foi apenas o valor do bem o que contou. Havia algo mais que estavam considerando e que emerge ao final da fala de Preta (08:17), quando diz: “... porque mesmo não sendo maior, o valor não é tão grande”. Essa fala indica que, na lógica de Preta, a diferença entre os dois também fora levada em consideração. Para nos certificarmos de que estava operando nessa direção, buscamos confirmar mais alguns significados produzidos, conforme podemos ver na transcrição a seguir:

Figura 5 - Outras impressões iniciais sobre a decisão (Transcrição de Vídeo 1)

\begin{tabular}{|l|l|l|}
\hline $07: 52$ & Lucas & Logo que olhou a gente pensou em comprar. \\
\hline $08: 05$ & Evelin & $\begin{array}{l}\text { A gente pensou em fazer conta. Não vamos tomar nenhuma decisão agora. } \\
\text { Melhor fazer as contas pra ver qual a melhor decisão. }\end{array}$ \\
\hline $08: 17$ & Preta & $\begin{array}{l}\text { Mas a gente achou a mesma coisa [se referindo ao dito pelo outro grupo] } \\
\text { que seria melhor comprar, porque mesmo sendo maior o valor não é tão } \\
\text { grande, e gente pensou no bem. }\end{array}$ \\
\hline $08: 25$ & Pesq & $\begin{array}{l}\text { Ah! Então.... O natural é que se o valor é maior então eu quero pagar } \\
\text { menos - vou alugar. Ai vem a segunda impressão que vocês disseram. } \\
\text { Poxa, mas no final eu tenho um bem. Mas não só isso. Se a prestação ali } \\
\text { fosse 2000 reais... }\end{array}$ \\
\hline $08: 46$ & $\begin{array}{l}\text { Pretae } \\
\text { Evelin }\end{array}$ & Aíseria diferente [rsss] \\
\hline $08: 48$ & Pesq & Tem uma coisa aí que vocês disseram agora que foia... \\
\hline $08: 54$ & $\begin{array}{l}\text { Pretae } \\
\text { Evelin }\end{array}$ & Diferença \\
\hline $08: 56$ & Pesq & Vocês acharam a diferença grande ou pequena? \\
\hline $08: 57$ & $\begin{array}{l}\text { Pretae } \\
\text { Evelin }\end{array}$ & Pequena \\
\hline $09: 00$ & Lucas & $\begin{array}{l}\text { Não! A gente achou a diferença pequena em relação à parcela. Mas } \\
\text { levando em consideração o valor total, depois que a gente fez a conta, a } \\
\text { diferençaé absurda. }\end{array}$ \\
\hline $09: 14$ & João & Achei a mesma coisa. \\
\hline $09: 16$ & José & Eu também. \\
\hline
\end{tabular}

Fonte: Elaborada pelos autores.

Quando perguntamos (08:25) o que fariam, se a prestação fosse de 2000 reais, Preta e Evelin disseram que "Aí seria diferente" (08:46), indicando que não era apenas ter um bem ao final o que influenciava essa impressão inicial.

Em seguida, os alunos do G1 levaram as prestações para o futuro, isto é, calcularam o valor da série dali a 20 anos, com o objetivo de comparar o total gasto nas duas opções após esse período, conforme a transcrição abaixo.

Figura 6 - Sobre o valor gasto no futuro com a compra do imóvel sob a ótica do G1.

\begin{tabular}{|l|l|l|}
\hline $09: 25$ & Lucas & $\begin{array}{l}\text { Aí, agente resolveu levar os valores para a data daqui a } 240 \text { meses. Seria } \\
\text { daqui a } 20 \text { anos. }\end{array}$ \\
\hline $09: 35$ & Pesq & Ah. Então vocês resolveram saber quanto as coisas valeriam no futuro? \\
\hline $09: 40$ & Lucas & Sim. \\
\hline $09: 42$ & Pesq & Por que vocês fizeram isso? \\
\hline $09: 46$ & Lucas & $\begin{array}{l}\text { Porque eu achei que seria uma forma mais concreta de comparar os } \\
\text { valores. }\end{array}$ \\
\hline $09: 53$ & Pesq & Você também achou uma forma concreta, Rogério. \\
\hline $09: 56$ & Rogério & $\begin{array}{l}\text { Eu achei que era interessante você saber quanto aquele valor que está } \\
\text { distribuído no tempo, você saber quanto ta valendo no futuro pra saber se } \\
\text { no futuro é mais .... assim quanto você teria gastado ao final, no total. }\end{array}$ \\
\hline $10: 10$ & Pesq & Você calculou quanto você gastou ou quanto vai ter? \\
\hline $10: 14$ & Rogério & Quanto teria gastado porque 900 são aplicados.... perdão, são pagos. \\
\hline
\end{tabular}

Fonte: Elaborada pelos autores. 
Na estratégia apresentada, fica evidente uma preocupação em considerar que o dinheiro se transforma no tempo, e essa transformação foi uma das principais operações realizadas pelos alunos de ambos os grupos. Entretanto, como veremos mais à frente, a operação levar para o futuro apresentou lógicas diferentes.

Em seguida, os alunos escolheram uma data para comparar os capitais para tomar a decisão, sendo o final dos 20 anos a data escolhida. Então calcularam o valor futuro da série uniforme formada pelo valor de cada parcela, chegando a um valor aproximado de 504.309 reais (vide figura 7).

Em seguida, encontram o valor futuro da entrada, considerando que seria aplicada à taxa da poupança fornecida, fazendo $30.000 \times 1,005^{240}=99.306$ reais e somaram os dois valores futuros encontrados, obtendo aproximadamente 613.615 reais.

A Figura a seguir mostra uma sequência de momentos que sintetiza a primeira solução apresentada pelo Grupo 1 .

Figura 7 - Síntese da estratégia da solução 1 do Grupo 1
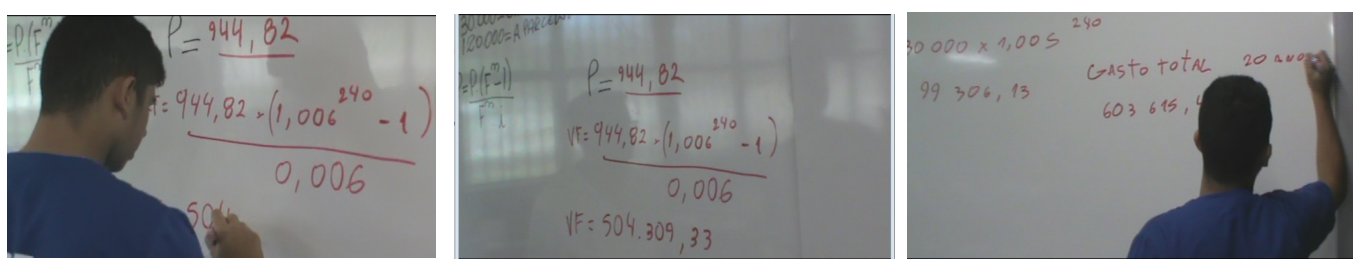

Fonte: Elaborada pelos autores.

Esse valor, entendido pelos alunos como o valor total gasto, foi considerado alto, segundo a fala de Lucas, o que motivou o grupo a procurar outra solução. Pela ótica do MCS, podemos dizer que há uma mudança na maneira de operar dos alunos, aqui motivada pelos resultados da primeira solução.Veja a fala abaixo:

Figura 8 - Mudança de direção para a segunda solução (transcrição de Vídeo 1)

\begin{tabular}{|l|l|l|}
\hline 14:38 & Lucas & $\begin{array}{l}\text { Esse aí é o valor gasto pra comprar a casa em } 20 \text { anos. Então a gente achou } \\
\text { esse valor [pausa] alto. E a gente resolveu fazer de outra forma. A gente } \\
\text { pensou na estratégia 2. Pensamos de uma forma diferente. A estratégia 2 } \\
\text { seria alugar a casa por } 700 \text { reais. }\end{array}$ \\
\hline $\mathbf{1 5 : 0 0}$ & Rogério & Eisso levando em consideração que o imóvel não tem valorização. \\
\hline
\end{tabular}

Fonte: Elaborada pelos autores.

O grupo apresenta uma segunda solução (que chamam de segundo passo), cuja estratégia central está apresentada na transcrição a seguir. 
Figura 9 - Início do segundo caminho traçado pelo G1 (Transcrição de Vídeo 2)

\begin{tabular}{|l|l|l|}
\hline $04: 42$ & Rogério & $\begin{array}{l}\text { Nós passamos para o segundo passo que seria pegar pagar os 700 } \\
\text { mensais e aplicar os } 244 \text { já que eu teria esse valor para aplicar } \\
\text { mensalmente. Seria aplicar os } 244 \text { mensalmente e aqueles } 30.000 \\
\text { também pegar e aplicar. }\end{array}$ \\
\hline $05: 05$ & Pesq & $\begin{array}{l}\text { Ah! Legal. Essa estratégia também é legal. Faz isso aí que eu quero ver. } \\
\text { Mas coloca só os resultados. Eu acho que as contas vocês já. }\end{array}$ \\
\hline $05: 10$ & Lucas & É isso [se referindo a uma conta no quadro] \\
\hline $05: 15$ & Pesq & Calma aí Lucas. Isso aí é a diferença? \\
\hline $05: 17$ & Lucas & Seria o valor da gente \\
\hline
\end{tabular}

Fonte: Elaborada pelos autores..

O segundo caminho, chamado por eles ao final de "alugar de forma diferente", pode ser resumido nas seguintes etapas:

Figura 10 - Etapas da segunda estratégia apresentada pelo Grupo 1.

1) Alugar o imóvel e aplicar a diferença entre o valor da prestação (que sairia do bolso se optassem por comprar) e o valor do aluguel, fazendo $944,82-700,00=244,82$.

2) Encontraram o valor futuro da série formada por 240 quantias iguais a 244,82 , calculando $V F=244,82 \times \frac{\left(1,005^{240}-1\right)}{0_{0,005}}=113.116,85$ reais.

3) Consideram ainda aplicar os 30 mil reais, pois no caso do aluguel esse valor não seria gasto para dar entrada no apartamento, obtendo o valor da aplicação no futuro igual a $30.000 \times 1.005^{240}=99.306$.

4) Por fim, somaram os dois valores futuros, obtendo um VF total igual a $113.116,85+$ $99.306,13=212.422,98$, o qual representa o quanto eles teriam acumulado em suas aplicações ao final de 20 anos.

Fonte: Elaborada pelos autores.

A partir dos resultados obtidos nessa segunda solução, o grupo decidiu que seria melhor alugar ao invés da comprar. O quadro abaixo e a sequência de figuras ilustram o processo final para a tomada de decisão.

Figura 11 - Síntese das etapas apresentadas na figura 12

(i) na primeira opção, o casal gasta 944,82 e ao final tem o apartamento no valor de 150 mil;

(ii) na segunda opção, o casal separa 944,82 mensais, paga o aluguel mensal de 700 reais, aplica a diferença de 244,82 , gerando um valor futuro total de $113.116,85$; além disso, investiria os 30 mil na poupança a $0,5 \%$ ao mês, gerando um valor futuro de $99.306,13$, o qual somado ao investimento anterior, resultaria em um valor total de $212.422,98$ ao final de 20 anos.

Fonte: Elaborada pelos autores. 
Figura 12 - Estratégias da segunda solução apresentada pelo Grupo 1

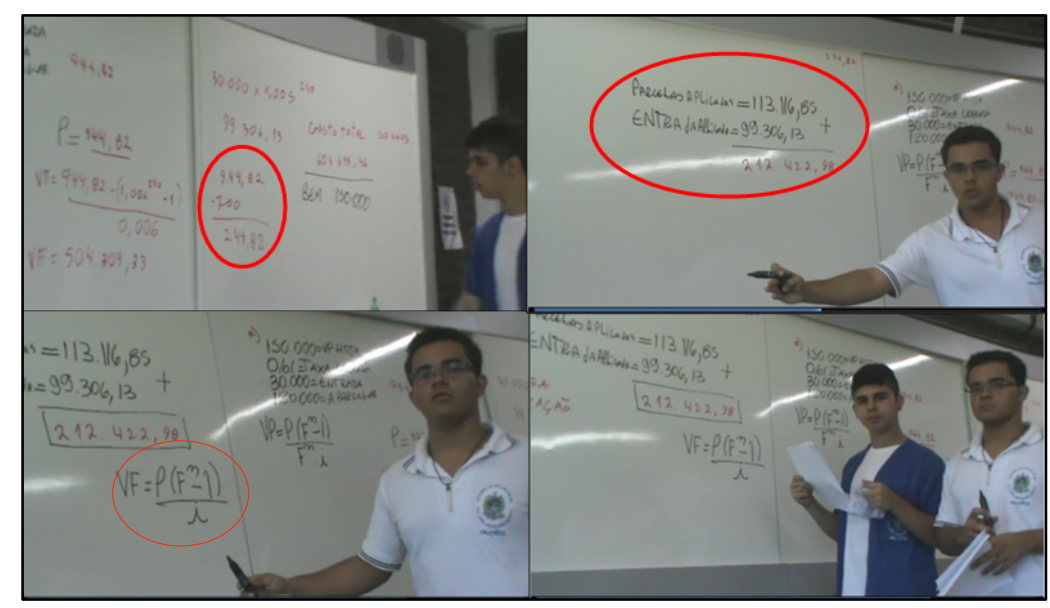

Fonte: Elaborada pelos autores.

Ao final da exposição do G1 as alunas do G2 fazem alguns questionamentos sobre as ideias apresentadas. Lucas e Rogério explicam para Evelin e Preta a estratégia que utilizaram. Identificamos diversos significados que foram sendo produzidos no decorrer das falas. Um exemplo foi o significado para valor futuro de uma série uniforme. Para Lucas (10:32) foi "valor futuro da união de todas as prestações"; para Preta (09:16) foi "Ao final de 20 anos vocês teriam 212 mil"; já para Evelin foi: "Entendi”.

Figura 13 - Diferentes significados produzidos para VF de uma série uniforme.

\begin{tabular}{|l|l|l|}
\hline $10: 27$ & Pesq & Eem nosso caso aqui? O que ela quer dizer? \\
\hline $10: 32$ & Lucas & Ovalor futuro da união de todas as prestaçoses. \\
\hline $10: 34$ & Pesq & $\begin{array}{l}\text { O valor futuro da [o pesquisador não tinha entendido direito o que } \\
\text { Lucas dissera] ...? }\end{array}$ \\
\hline $10: 35$ & Lucas & $\begin{array}{l}\text { União de todas as prestações. No caso somando todas as prestações } \\
\text { com seus respectivos juros. }\end{array}$ \\
\hline
\end{tabular}

Fonte: Elaborada pelos autores.

$\mathrm{Na}$ conclusão, o G1 usa as duas soluções encontradas, comparando-as. Dizemos componentes que, apesar de terem cometido um erro (isso dito por Lucas) em relação à taxa, o valor futuro ainda seria alto (mesmo sendo um pouco menor, segundo eles), e concluem dizendo que a estratégia 2 - alugar de "forma diferente" - seria a melhor decisão, considerando que não ocorra valorização do imóvel e nem do aluguel. A figura 14 mostra os argumentos de Lucas, sua movimentação no quadro e a conclusão do G1, comparando as duas estratégias utilizadas, escritas em duas partes diferentes do quadro. 
Figura 14 - Conclusão do G1 para a segunda estratégia.

\begin{tabular}{||l|l|l||}
\hline $12: 27$. & Lucas & $\begin{array}{l}\text { Então, a gente achou esse valor. Levando em consideração que a casa } \\
\text { não valorizou, aqui você gastaria esse dinheiro [se referindo aos } 504 \text { mil } \\
\text { da primeira solução] que seria menor porque a gente errou aqui na, nos } \\
\text { juros. Porém você perderia esse dinheiro para pagar a casa e você } \\
\text { ganharia vamos supor que você vendesse a casa você ficaria com tiraria } \\
150 \text { mil desse dinheiro [se referindo aos } 504 \text { mil] e você continuaria } \\
\text { perdendo. }\end{array}$ \\
\hline
\end{tabular}

Fonte: Elaborada pelos autores.

Figura 15 - Conclusão do G1 para a segunda estratégia - continuação.

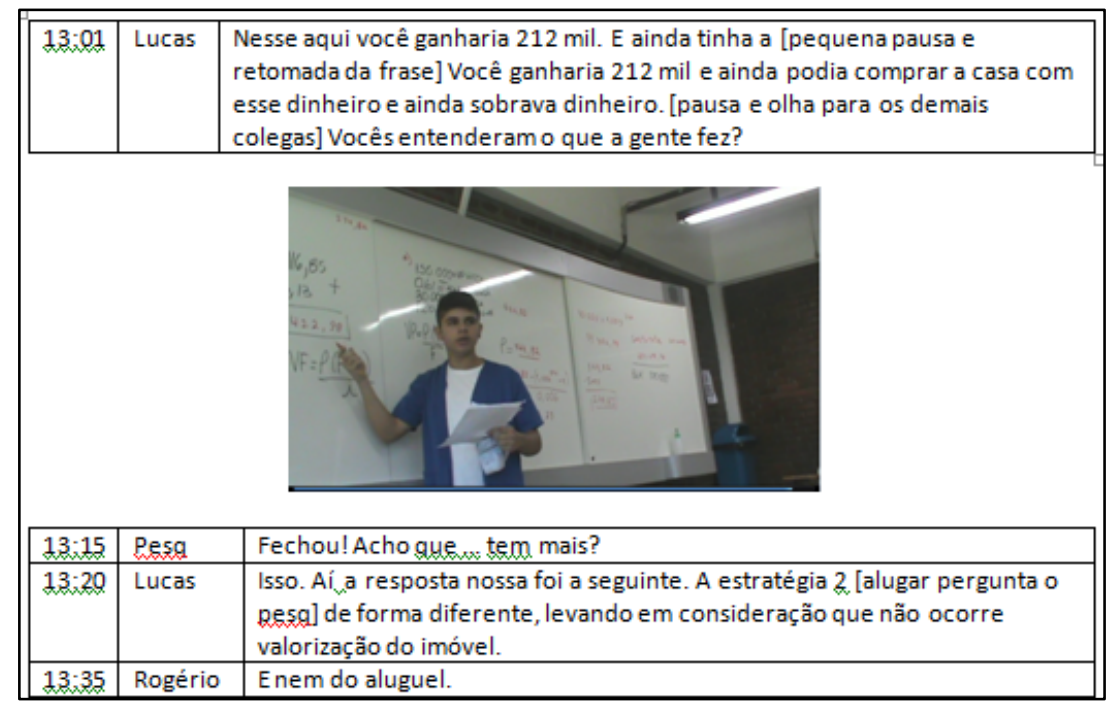

Fonte: Elaborada pelos autores.

\section{Análise das estratégias apresentadas pelo Grupo 2}

O G2 começa apresentando a situação que seria analisada conforme a transcrição a seguir:

Figura 15 - Momento inicial da apresentação do Grupo 2. (Vídeo 3)

\begin{tabular}{|c|c|c|}
\hline $01: 32$ & Preta & $\begin{array}{l}\text { Primeiro a gente pensou em somar qual seria a prestação se ele fosse } \\
\text { comprar o apartamento. A gente fez e deu o mesmo valor [apontando } \\
\text { para o quadro se referindo ao mesmo valor calculado pelo outro } \\
\text { grupo] }\end{array}$ \\
\hline $01: 42$ & Evelin & $\begin{array}{l}\text { Essaé a prestação. Aqui seria a soma dos } 700 \text { [se referindo ao valor de } \\
700 \times 240=168.000 \text { reais]. }\end{array}$ \\
\hline $01: 52$ & Preta & $\begin{array}{l}\text { Aía gente pegou quanto seria se ele pagasse } 700 \text { durante } 20 \text { anos e deu } \\
\text { esse valor. }\end{array}$ \\
\hline 01:53 & Pesq & Como é que vocês fizeram esses 168 mil? Multiplicaram por $240 ?$ \\
\hline $01: 58$ & Evelin & Sim. \\
\hline
\end{tabular}

Fonte: Elaborada pelos autores.

A forma como transformaram o dinheiro no tempo foi diferente, pois levaram os valores para o futuro, multiplicando o valor da prestação por 240 , fazendo 944,82 × $240=226.756,80$, e 
depois o valor do aluguel por 240, obtendo 700,00 x $240=168.000,00$ reais, conforme se pode ver nas imagens e na transcrição a seguir.

Figura 17 - Estratégia apresentada do G2.

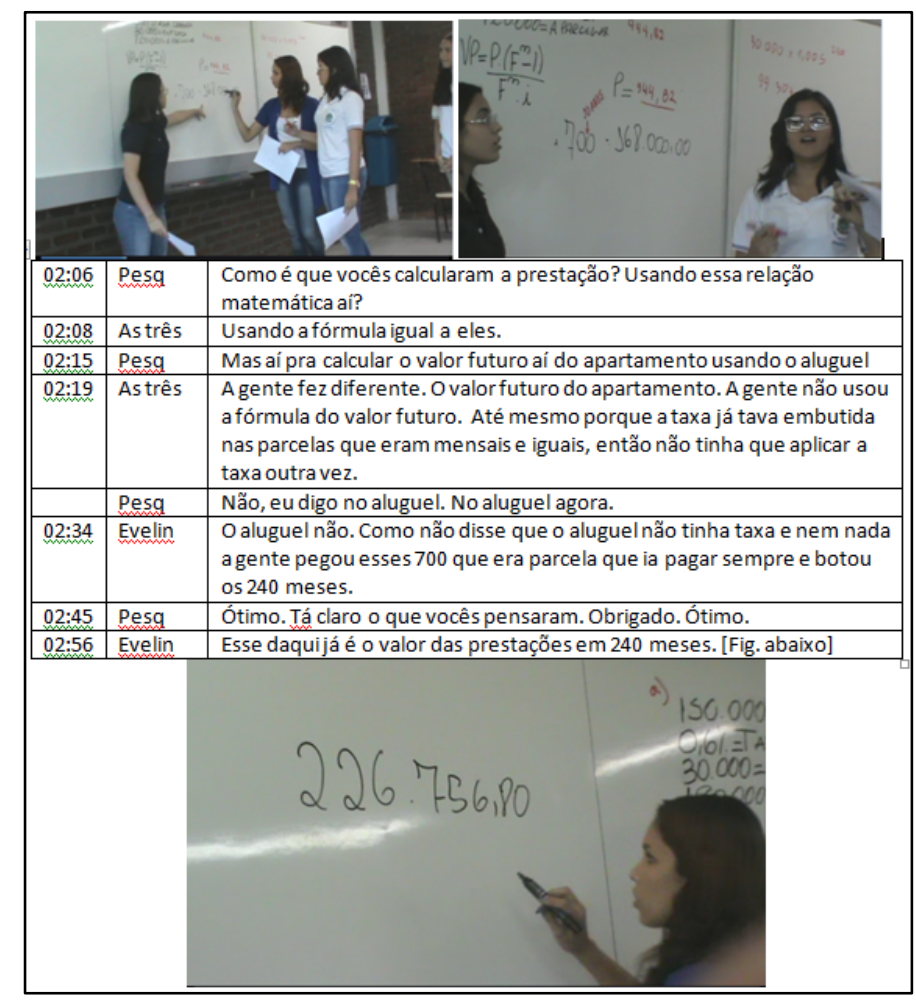

Fonte: Elaborada pelos autores.

As falas de Preta, Evelin e Bruna (02:19) indicam que o fato de a prestação calculada já ter juros embutidos, as impediu de operar na direção de que o valor das prestações no futuro seriam transformadas novamente. A lógica da operação de levar os valores para o futuro é diferente da lógica utilizada pelo G1. Operaram no que temos chamado em nossa pesquisa de campo semântico da acumulação aditiva do dinheiro no tempo, em que capitais referidos a datas diferentes são somados. E por outro lado, dizem que somaram os 240 aluguéis de 700 reais, para encontrar o outro valor futuro, por não ter uma taxa associada diretamente ao aluguel. Operaram no mesmo campo semântico (acumulação aditiva), mas utilizando legitimidades diferentes, isto é, foi legítimo não considerar a taxa, pois já fora considerada no cálculo da prestação, e não poderia ser repetida; e depois foi legítimo não considerar a taxa, pois não identificaram uma taxa associada diretamente ao valor do aluguel.

Enquanto o G1 transformou os valores duas vezes, usando a taxa de juros do banco para calcular o valor da prestação e em seguida para atualizar o valor das parcelas pagas, o G2 entendeu que isso não poderia acontecer (“... não tinha que aplicar a taxa outra vez.”) e operou na direção de somar as 240 prestações que seriam pagas para encontrar o valor futuro pago. 
Identificamos aqui uma alternância de campos semânticos pelos alunos. Para obter o valor da prestação, levou-se em consideração o campo semântico da transformação do dinheiro no tempo $^{6}$, em que os capitais só são somados, se estiverem referidos a uma mesma data, mas para obter um valor equivalente no futuro às parcelas pagas, operaram no campo semântico da acumulação aditiva.

Em seguida, operaram na direção de comparar o total gasto em cada opção. Como na compra "saem do bolso" 30 mil mais 240 prestações de 944,82, mas ao final tem-se um bem de 150 mil, e no aluguel "sai do bolso" 240 aluguéis de 700,00, e ao final não se tem nada, as alunas compararam os totais (descontando o valor do apartamento no caso da compra) e decidiram por comprar o imóvel, conforme mostram os argumentos a seguir:

Figura 18 - Conclusão do primeiro caminho do G2.

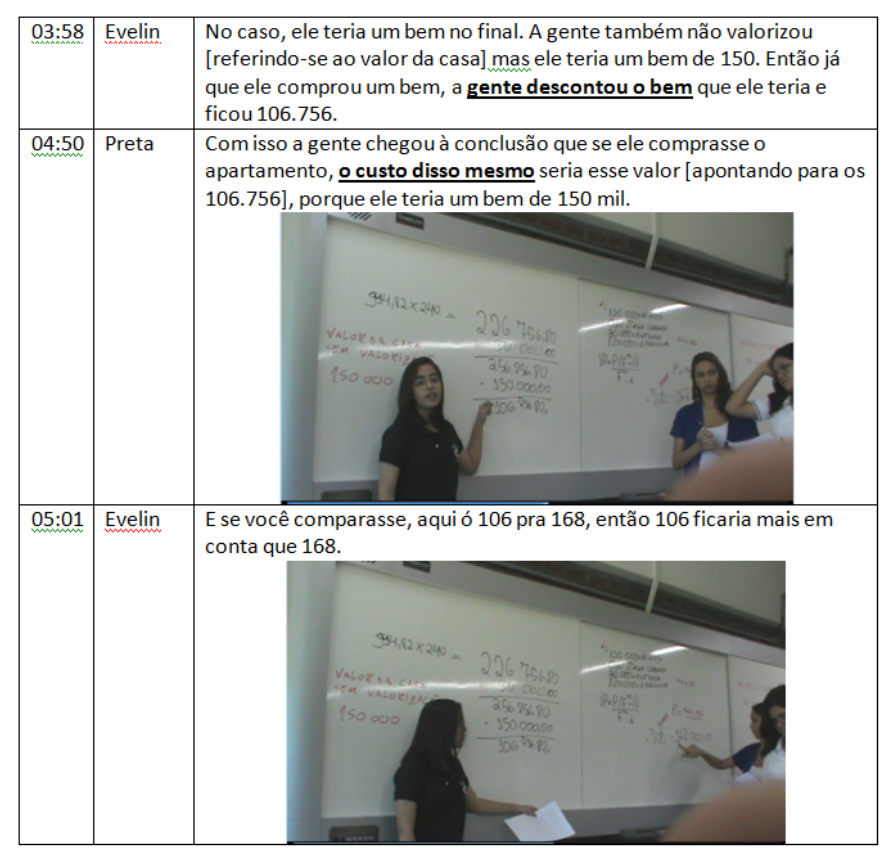

Fonte: Elaborada pelos autores.

A Estratégia do G2pode ser sintetizada na figura 18, que apresenta um resumo da estratégia utilizada e a sequência de imagens que ilustram tal estratégia.

\footnotetext{
${ }^{6}$ Esse é o campo semântico preferencial do professor de matemática financeira, apoiado nos conceitos da matemática financeira utilizado em economia e finanças.
} 
Figura 19 - Dinâmica da primeira estratégia exposta pelo G2.

1. Calcularam o valor da prestação do financiamento, obtendo $\mathrm{P}=944,82$
2. Calcularam o valor futuro da série de alugueis pagos, fazendo $\mathrm{VF}_{2}=700 \times 240=168.000,00$
3. Calcularam o valor futuro da série de prestações, fazendo $\mathrm{VF}_{1}=944,82 \times 240=226.756,80$
4. Somaram a esse valor, os 30.000 que o casal tinha gastado, obtendo um gasto total de
$256.756,80$.
5. Calcularam a diferença $256.756,80-150.000,00=106.756,80$
6. Compararam esse valor de $106.756,80$ ("custo disso mesmo" de comprar o apartamento) com
7. Cos $168.000,00$ do aluguel.

Fonte: Elaborada pelos autores.

Figura 20 - Imagens da primeira estratégia exposta pelo G2.

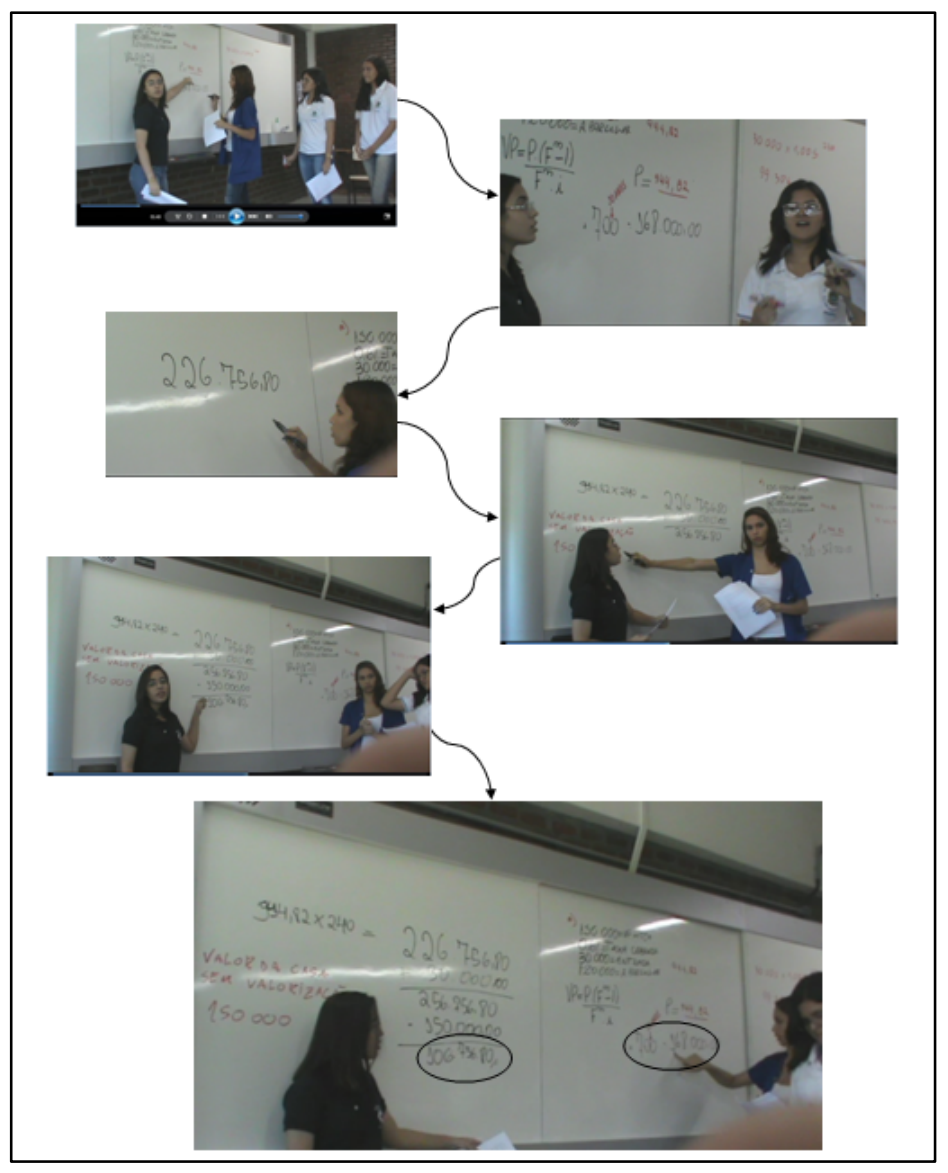

Fonte: Elaborada pelos autores.

As alunas do G2 também apresentaram outro pensamento, em que os quatro primeiros passos são iguais ao anterior, conforme apresentamos no quadro a seguir. 
Figura 21 - Dinâmica da segunda estratégia apresentada pelo G2.

5. Fazem a diferença $256.756,80-168.000,00$, obtendo $88.756,80$.

6. Comparam essa diferença de $88.756,80$ com o valor da casa sem correção ou valorização que é de $150.000,00$.

7. Concluem dizendo que seria melhor comprar, pois $88.756,80$ seria como comprar uma casa, comparando com o aluguel.

Fonte: Elaborada pelos autores

Figura 22 - Imagens da primeira estratégia exposta pelo G2

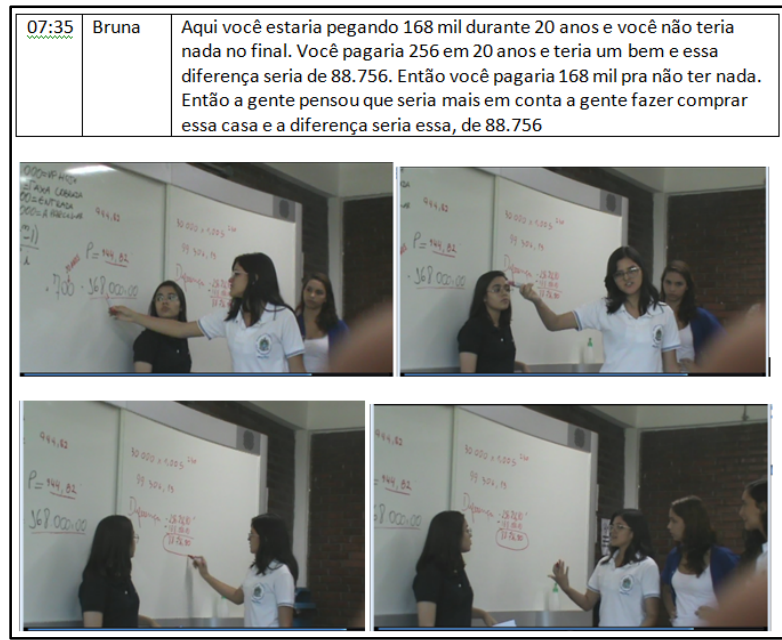

\begin{tabular}{|l|l|l|}
\hline $08: 02$ & Evelin & $\begin{array}{l}\text { E supondo que você comprasse uma casa, por digamos } 88 \text { mil que é a } \\
\text { diferença do pagar aluguel, ta muito barato uma casa por } 88 \text { mil. }\end{array}$ \\
\hline 08:14 & Pesq & Então a decisão?É melhor ter comprado? \\
\hline & Evelin & Sim. Melhor é comprar. Longa pausa. \\
\hline
\end{tabular}

Fonte: Elaborada pelos autores

Enquanto o G1 concluiu que o melhor era alugar, investindo a diferença entre o valor da prestação e o valor do aluguel, o G2 chegou à conclusão, nos caminhos apresentados, de que o melhor era comprar a casa, pois o custo com as prestações era vantajoso em relação ao custo do aluguel, devido ao valor da casa, tudo isso ao final de 20 anos.

O pensamento utilizado pelo G2 de somar as prestações, e depois os aluguéis, para determinar o total gasto no futuro, constituído pelas alunas como valor futuro total gasto com prestações e com aluguéis, respectivamente, é uma operação muito realizada pelos alunos, baseado no que temos observado em nossa prática docente. Mas essa prática pode levar a conclusões diferentes daquelas pensadas levando-se em consideração a transformação do dinheiro no tempo, como visto na solução do G1, por exemplo.

Não queremos aqui dizer se isso está certo ou errado, pois o objetivo era ler o outro, analisar os significados e conhecimentos produzidos, procurando, para isso, entender em quais direções os alunos operaram, quais objetos constituíram nesse processo e a lógica de suas operações. 
Nosso objetivo aqui é entender o pensamento matemático dos estudantes e sua articulação com outros aspectos no processo de tomada de decisão em tarefas envolvendo uma situação financeira dada. Certamente esse entendimento pode ajudar professores de matemática a criar estratégias para convidar os alunos a pensarem em outra direção, como, por exemplo, a da minimização dos custos do ponto de vista financeiro, utilizando a taxa disponível ao comprador.

Mas gostaríamos neste ponto de apresentar uma breve análise de porque esse tipo de pensamento, tão comum e usual, pode gerar sérios problemas e consequências. Quando dispomos de uma taxa diferente de zero, os capitais se transformam no tempo. Somar as quantias sem transformá-las é considerar que o dinheiro não se transforma no tempo, ou seja, considerar uma taxa zero, ainda que as pessoas não façam ou pensem nisso de forma consciente. Essa estratégia é plausível se uma pessoa optar por não utilizar sua taxa em uma operação. Ou ainda, em situações econômicas em que a taxa de juros, bem como a taxa de inflação, seja zero, o que é bem improvável de acontecer, pelo menos no contexto brasileiro.

Assim, considerando situações em que as taxas de juros e inflação são diferentes de zero (como ocorre no Brasil há muito tempo), somar quantias em épocas diferentes pode gerar diversos problemas. Vejamos dois exemplos.

Consideremos que uma pessoa financiou um carro, a uma taxa de juros de $2 \%$ ao mês, e está querendo se livrar da dívida. Para isso deseja antecipar as quatro últimas prestações de 1000 reais que vencem nos quatros meses seguintes. Quanto ele está devendo hoje? O pensamento mais natural é o aditivo, ou seja, pensar que a dívida é de 4000 reais. Mas não é. Na maioria dos financiamentos, ele teria direito a um desconto, pois as prestações atuais não valem 1000 reais, pois cada uma delas possui juros embutidos. Somar, nesse caso, pode levar o consumidor a ser lesado em seus direitos.

Consideremos que uma pessoa faça um empréstimo de 1000 reais, a uma taxa de juros de $10 \%$ ao mês sobre o saldo devedor, e pague 100 reais mensais nos dois primeiros meses. O saldo devedor no terceiro mês não será $1000-200=800$; também não será de $1.331-200=1.131$ reais. Nesses dois casos, a soma de quantias referidas a datas diferentes gerou um saldo devedor diferente do que deveria ser cobrado pelo credor. No primeiro desconsiderou-se a taxa cobrada, e o credor não aceitaria isso, pois foi acordada uma taxa de juros. No segundo caso, gerou-se um saldo devedor maior do que o produzido a partir das regras acordadas.

\section{Análise da articulação do conhecimento matemático com outros conhecimentos}

No momento final do encontro, os alunos apresentaram diversos fatores que influenciariam na tomada de decisão das pessoas nessa situação. 
O primeiro fator a ser considerado foi o efeito da inflação na tomada de decisão. A transcrição a seguir apresenta alguns significados que os alunos produziram para possíveis impactos da inflação na tomada de decisão, conforme se vê nas seguintes falas:

Figura 23 - Significados produzidos pelo G1 para o impacto da inflação na tomada de decisão.

\begin{tabular}{|l|l|l|}
\hline 11:30 & Roger & A gente tem que considerar também os fatores exógenos. \\
\hline 11:35 & Pesq & Fatores Exógenos!? O que significa isso? \\
\hline $11: 38$ & Roger & $\begin{array}{l}\text { Fatores externos. Fatores que influenciam além do valor do aluguel, } \\
\text { além do valor da casa. O valor de inflação, o valor do salário que } \\
\text { aumenta. }\end{array}$ \\
\hline $11: 50$ & Pesq & Como você acha que a inflação influenciaria nisso? \\
\hline $11: 52$ & Roger & $\begin{array}{l}\text { O dinheiro que eu teria pra bancar, pra pagar as parcelas poderia ser } \\
\text { diferente, de acordo com a inflação do período. }\end{array}$ \\
\hline $12: 02$ & Pesq & Porquê? \\
\hline $12: 04$ & Roger & $\begin{array}{l}\text { Porque a minha cesta básica, por exemplo, pode estar mais cara e aí } \\
\text { talvez eu não tenha o dinheirototal pra ir pagandoessas parcelas. }\end{array}$ \\
\hline
\end{tabular}

Fonte: Elaborada pelos autores.

A inflação, segundo Roger, impacta o valor dos produtos, o que modifica a capacidade de compra e, portanto, de pagamento do aluguel ou das parcelas.

Outros aspectos, além da inflação, que poderiam influenciar a escolha entre comprar e alugar foram aparecendo, à medida que os grupos apresentaram suas considerações para os itens $c$ a $f$. Dentre eles, temos:

Figura 24 - Outros aspectos emergentes dos discursos envolvendo tomada de decisão.

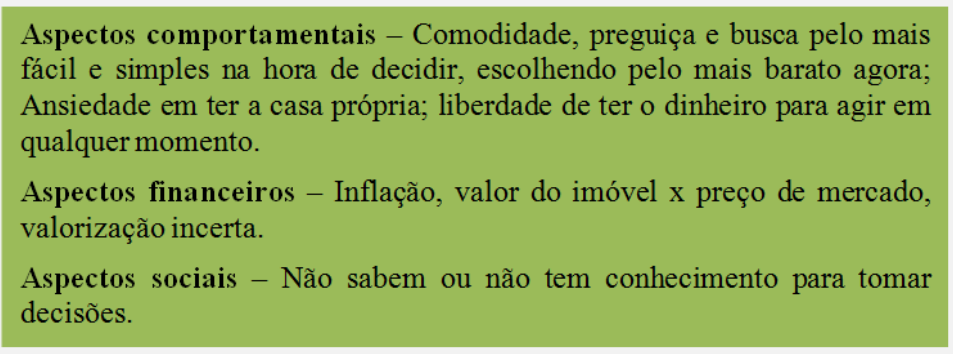

Fonte: Elaborada pelos autores.

Para o item c, cuja pergunta era "Qual a estratégia que a maioria das pessoas usaria?”, o G1 disse que a maioria compraria o imóvel, justamente a decisão oposta ao que disseram inicialmente, enquanto que o G2 disse que a maioria alugaria, em oposição à escolha inicial do grupo. As justificativas estão apresentadas no quadro a seguir: 
Figura 25 - Resumo das respostas e justificativas para o item c.

\begin{tabular}{|c|c|}
\hline \multicolumn{2}{|c|}{ Grupo 1} \\
\hline Decisão do Grupo 1 & Alugar \\
\hline $\mathrm{O}$ que a maioria faria? & Comprar \\
\hline \multicolumn{2}{|c|}{ Justificativas: } \\
\hline \multicolumn{2}{|c|}{$\begin{array}{l}1 \text { - Devido à falta de Conhecimento da Matemática } \\
\text { Financeira } \\
2 \text { - Ansiedade de ter sua casa própria. Se ela [se } \\
\text { referindo a uma pessoa do conjunto da maioria] tem } \\
\text { dinheiro para dar a entrada e comprar parcelado, ela } \\
\text { vai comprar } \\
3 \text { - Se ela não tiver o dinheiro, não tem outra opção, } \\
\text { ela vai alugar. }\end{array}$} \\
\hline
\end{tabular}

\begin{tabular}{|c|c|}
\hline \multicolumn{2}{|c|}{ Grupo 2} \\
\hline Decisão do Grupo 2 & Comprar \\
\hline $\mathrm{O}$ que a maioria faria? & Alugar \\
\hline \multicolumn{2}{|c|}{ Justificativas: } \\
\hline \multicolumn{2}{|c|}{$\begin{array}{l}1 \text { - Não sabem. } \\
2 \text { - Não fariam as contas por preguiça. } \\
3 \text { - As pessoas simplesmente diriam: "A parcela } 700 \text { é } \\
\text { menor que a prestação de } 944 \text {, logo vou alugar". } \\
\text { Prefiro pagar menos do que pagar mais. }\end{array}$} \\
\hline
\end{tabular}

Fonte: Elaborada pelos autores.

Para o itens $d$ e $e$, cuja pergunta era: "Considerando que o imóvel se valorize a uma taxa de 3\% ao ano, você mudaria de opinião? Justifique. E se fosse 6\% ao ano?", os dois grupos calcularam o valor da casa após 20 anos, encontrando um valor de aproximadamente 271 mil reais, conforme ilustra a figura a seguir.

Figura 26 - Impacto da inflação na tomada de decisão.
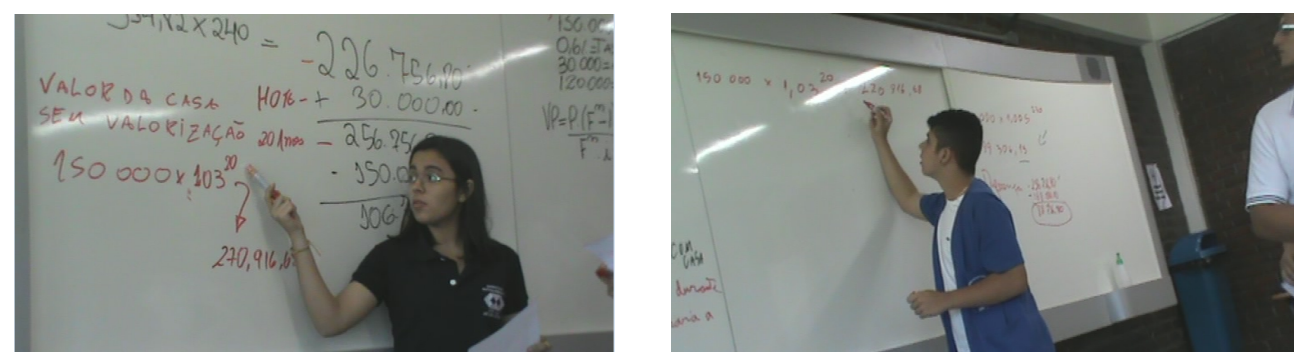

Fonte: Elaborada pelos autores.

O G1 mudou de decisão, pois o valor do apartamento ficou maior que o acumulado na estratégia anterior. O G2 manteve sua decisão, pois se sem valorização já compravam, valorizando ficou ainda mais favorável, segundo os alunos. Essas ações foram coerentes com as legitimidades entendidas em cada grupo. As decisões dos grupos para esses dois itens e suas justificativas estão apresentadas no quadro abaixo.

Figura 24 - Quadro comparativo das decisões apresentadas considerando o efeito da valorização do imóvel.

\begin{tabular}{|c|c|}
\hline Grupo 1 & Grupo 2 \\
\hline Decisão anterior & Decisão anterior \\
\hline Nova decisão & Nova decisão \\
\hline Justificativas: & Justificativas: \\
\hline $\begin{array}{l}\text { Mudaram a decisão, pois compararam o valor total } \\
\text { acumulado de } 212 \text { mil reais ao final de } 20 \text { anos, } \\
\text { obtido da estratégia anterior, com o novo valor da } \\
\text { casa considerando a valorização de } 3 \% \text { ao ano, que } \\
\text { foi de } 271 \text { mil reais. Como a casa vale mais do que o } \\
\text { dinheiro acumulado, então optaram por mudar de } \\
\text { opinião. Isso se manteve para a taxa de } 6 \% \text { ao ano. }\end{array}$ & $\begin{array}{l}\text { Mantiveram a decisão, nos dois casos, pois se sem a } \\
\text { valorização do apartamento elas já comprariam, } \\
\text { considerando a valorização a situação ficou ainda mais } \\
\text { favorável, com o valor do imóvel passando a valer } 271 \\
\text { mil e } 481 \text { mil reais para as taxas de } 3 \% \text { e } 6 \% \text {, } \\
\text { respectivamente, de valorização anual. }\end{array}$ \\
\hline
\end{tabular}

Fonte: Elaborada pelos autores. 
A valorização do imóvel foi um aspecto importante na discussão final, pois os dois grupos constituíram como objeto o valor do apartamento e o usaram na estratégia de escolher sempre a opção que apresentasse o maior valor acumulado.

Registramos ainda outro aspecto sobre valorização que emergiu no discurso de Evelin, quando disse: “Tem que ver se esse apartamento vale realmente 150 mil, se vale esse preço". Nessa fala ela se preocupa com o valor atual do imóvel, levantando uma questão importante relacionada à diferença entre preço e valor, em um dado momento. Ela também considerou que era preciso ver o preço de outros imóveis semelhantes àquele no bairro, para "não comprar uma casa mais cara do que vale" ou seja, considerou que seria importante uma pesquisa de mercado para avaliar o valor do imóvel.

Finalmente, para o item $f$, cuja pergunta era "Considere todas as premissas anteriores, e que o aluguel seja reajustado anualmente a uma taxa de 6\% ao ano. Qual seria a sua decisão? Justifique.”, o Grupo 1 não conseguiu terminar dentro do tempo, e o Grupo 2 apresentou um argumento que pode ser resumido no quadro abaixo.

Figura 28 - Análise do Grupo 2 sobre o impacto do reajuste do aluguel na tomada de decisão.

$\checkmark$ Considerar um aluguel de 8.400 no primeiro ano

$\checkmark$ Atualizar esse gasto anual à taxa de $6 \%$ ao ano, fornecida na tarefa, obtendo o valor anual que seria gasto em cada um dos 19 anos seguintes, produzindo uma sequência com 20 gastos anuais.

$\checkmark$ Depois disso, somaram esses gastos anuais estimados, obtendo um valor de 308.998 reais.

$\checkmark$ Considerando que o gasto total com prestações e entrada foi de $226.756,80$ e que a casa teria um valor de 271 mil reais (para valorização anual de $3 \%$ ) e de 481 mil reais (para um taxa de $6 \%$ ao ano de valorização), então a decisão foi mantida em todos os itens, pois seria mais vantajoso gastar 226 mile ter um bem de $271 \mathrm{mil}$ do que gastar 308 mil e não ter um bem ao final.

Fonte: Elaborada pelos autores.

Ao final das explicações, seguiu-se uma discussão em que outros aspectos surgiram, conforme sintetizados no quadro a seguir.

Figura 29 - Aspectos não matemáticos apresentados pelos alunos que podem influenciar na tomada de decisão da situação apresentada.

a oportunidade de compra que pode não voltar mais; o momento econômico da região;

$\checkmark \quad$ a liberdade de pode usufruir ou de aproveitar outras oportunidades com o dinheiro aplicado, mesmo que fique um pouco abaixo do valor da casa (em outras palavras, abordaram o aspecto da liquidez, mas sem dizer ou definir dessa forma);

$\checkmark \quad$ a possibilidade de outros investimentos dispondo de dinheiro que não seriam possíveis com a casa;

$\checkmark \quad$ a liberdade de uso do dinheiro optando pelo aluguel e falta de liberdade de uso se comprar a casa;

$\checkmark$ o risco de perder o emprego e os efeitos disso para quem aluga (menos danosos)e para quem compra (mais danosos); mudança de gosto do casal ao longo de 20 anos influenciando na estratégia, dentre outros.

Fonte: Elaborada pelos autores. 
A partir desses registros, identificamos uma rede de significados produzidos pelos alunos para as mudanças de cenários que foram sendo apresentadas, mostrando que os conhecimentos matemáticos produzidos coexistem com outros aspectos financeiros, culturais e comportamentais no processo de tomada de decisão.

\section{Considerações Finais}

Nesse artigo analisamos a construção e utilização de ideias matemáticas e financeiras por estudantes de Ensino Médio e como foram articuladas com outros conhecimentos em uma atividade envolvendo a decisão entre comprar ou alugar um imóvel.

Os resultados preliminares apontam para dois caminhos importantes. Um deles indica que estudantes de Ensino Médio, a partir de alguns objetos que constituíram ao longo do ano letivo, nas aulas de matemática financeira, produziram conhecimentos e significados para analisar uma situação financeira envolvendo a compra ou aluguel de um imóvel, a partir de diferentes significados produzidos com base em objetos por eles constituídos, como o valor da prestação de um financiamento em parcelas iguais, o valor futuro de uma aplicação, inflação, valorização do imóvel e reajustes do aluguel, dentre outros. Os aspectos matemáticos e financeiros foram considerados pelos alunos e os resultados obtidos produziram, em alguns casos, mudança de escolha de alternativas.

Outro caminho foi a apresentação pelos estudantes de outros aspectos que estariam relacionados às suas escolhas, alguns dos quais influenciando uma mudança de decisão, tais como a inflação e a valorização do imóvel, conforme suas falas no transcorrer do encontro. Aspectos comportamentais, sociais e financeiros estiveram presentes nos discursos dos estudantes, mostrando como acreditavam que tais fatores influenciaram ou poderiam influenciar na tomada de decisão no interior da atividade.

Os dois grupos usaram como critério principal para tomar decisão o ponto de vista financeiro, isto é escolheram a opção que proporcionasse o maior retorno financeiro, ao final de 20 anos, tomando como base a comparação do valor total acumulado em cada uma das opções. Mesmo esse prazo sendo tão longo, e mesmo dizendo e apresentando muitos fatores que poderiam interferir na decisão, apresentaram uma solução de um ponto de vista matemático e financeiro.

Identificamos uma rede complexa de objetos sendo constituídos, em que a transformação do dinheiro no tempo, representada através de diferentes significados, contribuiu para a construção de soluções que serviram de apoio à tomada de decisão. 
Os resultados apontam também para a importância da abordagem de situações financeiras, através de tarefas que convidem os alunos a construir ideias matemáticas, bem como estimular a articulação de conhecimentos, matemáticos e não matemáticos, na análise de situações financeiras.

\section{Referências}

BARROSO, D. F. Uma proposta de curso de serviço para a disciplina matemática financeira: mediada pela produção de significados dos estudantes de administração. Dissertação (Mestrado). Universidade Federal de Juiz de Fora (UFJF), Juiz de Fora, 2013.

BRITTO, R. R. Educação Financeira: Uma Pesquisa Documental Crítica. Dissertação (Mestrado). Universidade Federal de Juiz de Fora (UFJF), Juiz de Fora, 2012.

CAMPOS, A. B., Investigando como a Educação Financeira Crítica pode contribuir para tomada de decisões de consumo de jovens indivíduos-consumidores. Dissertação (Mestrado). Universidade Federal de Juiz de Fora (UFJF), Juiz de Fora, 2013.

KISTEMANN Jr., M.A. Sobre a produção de significados e a tomada de decisão de indivíduosconsumidores. 2011. Tese de Doutorado - UNESP - Rio Claro-SP, 2011.

LINS, R. C. A framework for understanding what algebric thinking is. 330p. Thesis(Phd) University of Nottingham, Nottingham. 1992.

LINS, R.C. Epistemologia, História e Educação Matemática: tornando mais sólidas as bases de pesquisa. Revista da SBEM - SP, Campinas, v.1(1), 75-79, 1993.

LINS, R. C. (1999) Por que discutir teoria do conhecimento é relevante para a Educação Matemática. In: Bicudo, M. A. V. (org.). Pesquisa em Educação Matemática: concepções e perspectivas. São Paulo: Editora da UNESP, .75-94.

MUNIZ, I. Jr. Educação Financeira: Conceitos e Contextos para o Ensino Médio. In: X ENCONTRO NACIONAL DE EDUCAÇÃO MATEMÁTICA, 11., 2010, Salvador. Anais... Salvador, Brasil: X ENEM, 2010. p. 1-11.

MUNIZ, I. Jr; JURKIEWICZ, S. Educação Econômico-Financeira: uma nova perspectiva para o Ensino Médio. In: VII CONGRESO IBEROAMERICANO DE EDUCACION

MATEMATICA, 12., 2013, Curitiba. Actasdel VII CIBEM, Montevideo, Uruguai: p. 3125-3135.

. Ambientes de Aprendizagem e Educação Financeira no Ensino Médio: potencialidades e ¡imitações. In I SEMINÁRIO DE EDUCAÇÃO FINANCEIRA ESCOLAR E EDUCAÇÃO MATEMÁTICA, 13, 2014, Juiz de Fora, UFJF. Anais do I SEFE, Minas Gerais, Brasil. I SEFE, 2014.

MUNIZ JR, I. Uma investigação sobre a abordagem de situações financeiras envolvendo taxas de juros no Brasil em um curso pós-médio. In: XIV CONFERẾNCIA INTERAMERICANA DE EDUCACION MATEMATICA, 12., Tuxtla, 2015a. Actasdel XIV CIAEM, Tuxtla, México. (Aceito em Jan/2015)

MUNIZ JR, I. Produção e articulação de conhecimentos matemáticos e financeiros por alunos do Ensino Médio: a dinâmica de uma poupança programada. In: $4^{\circ}$ Simpósio Internacional de Pesquisa em Educação Matemática, 12. Ilhéus, 2015b. Bahia, Brasil. 
PNLD 2015. Guia de livros didáticos de Matemática para o Ensino Médio 2015. Disponível em http://www.fnde.gov.br/programas/livro-didatico/guias-do-pnld/item/5940-guia-pnld-2015.

POWELL. A. B.; FRANCISCO, J. M.; MAHER, C. A. Uma abordagem à análise de Dados de Vídeo para Investigar o Desenvolvimento de Ideias e Raciocínios Matemáticos de Estudantes. Bolema, Rio Claro: Unesp, Programa de Pós Graduação em Educação Matemática, n.21, ano 17, 2004.

POWELL, A. B; QUINTANEIRO, W.S. Métodos de Pesquisa em Educação Matemática usando escrita, vídeo e internet. Mercado de Letras. Rio de Janeiro, 2015.

ROLIM, M.R.L.B; MOTA, M.S. O estado da arte das pesquisas em matemática financeira nos programas de mestrado e doutorado da área de ensino da Capes. São Paulo: Educação Matemática Pesquisa, v.16, n.2, pp. 537-556, 2014.

SILVA, A. M. (2003) Sobre a Dinâmica da Produção de Significados para a Matemática. 243p.

Tese de Doutorado - Universidade Estadual Paulista, Rio Claro, SP. 2003.

SAITO, A. T. Uma contribuição ao desenvolvimento da educação em finanças no Brasil.

Dissertação de Mestrado. FEA/USP - São Paulo, 2008.

SKOVSMOSE, O. Educação Matemática Crítica: a questão da democracia. Campinas: Papirus. 2001. 